\title{
Rancang Bangun Aplikasi Travel Booking Berbasis Android Pada Transwisata Travelindo Tour And Travel Malang
}

\author{
Ika Yuni Kristiana ${ }^{1}$, Citra Kurniawan ${ }^{2}$ \\ Sekolah Tinggi Teknik Malang ${ }^{12}$ \\ yuniika6@gmail.com ${ }^{1}$ \\ airakurniawan@gmail.com²
}

\begin{abstract}
ABSTRAK
Penelitian ini bertujuan untuk mengetahui pembuatan dan perancangan aplikasi pemesanan travel berbasis android. Metode pemesanan travel berbasis android ini bertujuan untuk lebih memudahkan pelanggan dari Transwisata Travelindo Tour and Travel dalam hal booking travel. Untuk ruang lingkup penelitian hanya dilakukan pada Transwisata Travelindo Tour and Travel dan sistem aplikasi tersebut berisi tentang informasi jadwal keberangkatan, rute keberangkatan travel, serta tarif atau harga travel.
\end{abstract}

Sistem pembayaran yang digunakan dalam hal pemesanan travel diharuskan pelanggan melakukan proses transfer sesuai dengan total biaya via rekening bank di Transwisata Travelindo. Payment akan dinyatakan berhasil oleh admin jika pembayaran sesuai dengan biaya pemesanan travel. Proses selanjutnya admin akan mengirimkan tiket travel ke email pelanggan. Untuk laporan keuangan yang diterima akan terperinci dan jelas yang bertujuan mempermudah untuk laporan sehingga semua pekerjaan tidak keseluruhannya menggunakan cara manual.
Hasil kelayakan aplikasi ini dari ahli materi memiliki presentase $82 \%$, dari ahli media memiliki presentase $80 \%$. Berdasarkan dari hasil pengukuran kelayakan tersebut, maka dapat disimpulkan bahwa Aplikasi Booking Travel Berbasis Android ini dinyatakan layak.

Kata Kunci: Booking Travel, Android

\section{ABSTRACT}

This study aims to determine the manufacture and design of travel applications based on android. This travel-based travel ordering method aims to further facilitate customers of Travel in terms of booking travel. For the scope of research is only done on Travelindo Travel and the application system contains information about the departure schedule, travel departure routes, and fares or travel prices.

The payment system used in the case of travel reservations required customers to make the transfer process in accordance with the total cost via bank account in Transwisata Travelindo. Payment will be declared successful by the admin if the payment in accordance with the cost of booking travel. The next process admin will send travel ticket 
to customer's email. For the financial statements received will be detailed and clear which aims to simplify the report so that all work is not entirely using the manual way.

The feasibility of this application from the material expert has a percentage of $82 \%$, from the media expert has an $80 \%$ percentage. Based on the results of these feasibility measures, it can be concluded that the Travel Booking Application Based Android is declared feasible.

Keyword: Booking Travel, Android

\section{PENDAHULUAN}

Kemajuan teknologi pada saat ini memang sangat canggih dan pastinya dimanfaatkan oleh semua segmen usia. Teknologi informasi saat ini sangat membantu dan memudahkan masyarakat di dalam kehidupan sehari-hari secara maksimal. Perusahaan dan perorangan juga menggunakan secara positif teknologi ini untuk agar lebih maju dan lebih lagi dari yang sebelumnya. Kemajuan teknologi yang dapat berupa media website atau media mobile dan menimbulkan energi yang positif dikarenakan memberikan variasi yang baru dan lebih canggih sehingga dapat meningkatkan kualitas perusahaan dalam mengembangkan dalam hal penawaran jasa kepada konsumen, sehingga menimbulkan persaingan terhadap satu perusahaan dengan perusahaan lain yang bergerak di bidang jasa travel.
Travel sangat erat kaitannya dengan proses pemesanan atau reservasi, dimana konsumen akan memesan suatu tiket sebelum keberangkatan ke kota tujuan. Sistem manual booking travel yang dilakukan oleh pelanggan melalui perantara telepon ataupun datang ke agen secara langsung menjadikan kelemahan dari system manual booking travel. Pelanggan harus konfirmasi tentang jadwal keberangkatan travel bahkan harus menunggu lama untuk menanyakan jadwal keberangkatan mana yang masih kosong atau informasi dari yang lainnya.Itu dapat menyebabkan waktu pelanggan menjadi habis hanya sekedar mengurus untuk booking travel. Dalam hal ini report untuk booking travel juga masih berjalan secara manual contohnya setiap transaksi pemesan travel masih dicatat di dalam buku dan masalah ini dapat menyebabkan ketidakakuratan database data yang dapat mengakibatkan terhambatnya proses booking travel oleh agen travel.

Dengan adanya booking travel melalui aplikasi android ini merupakan bentuk penawaran kenyaman bagi konsumen jasa transportasi travel yang tidak perlu lagi menanyakan dan mencatat jadwal keberangkatan dari travel tersebut. Sehingga sistem ini dirancang sedemikian rupa untuk calon penumpang dalam melakukan reservasi tiket dan memilih tempat duduk sesuai keinginan calon penumpang. Sistem tersebut dapat 
memudahkan proses booking travel untuk para konsumen ataupun calon penumpang serta dapat memantau bagaimana laporan atau report dari booking travel secara otomatis, dan lebih menjalin hubungan yang baik antara perusahaan dan pelanggan.

\section{TINJAUAN PUSTAKA}

\subsection{Sistem}

Sistem adalah suatu hubungan kerja yang terbentuk atas prosedur-prosedur yang berhubungan dan berkumpul secara bersama untuk melakukan kegiatan dan dapat menyelesaikan suatu sasaran yang sudah ditentukan (Jogiyanto, 2005). Dapat disimpulkan bahwa pengertian dari sistem adalah kumpulan objek yang membentuk suatu jaringan yang saling berhubungan satu sama lain dan bekerja untuk melakukan suatu kegiatan guna mencapai sasaran tertentu.

\subsection{Sistem Reservasi Tiket Travel}

Reservasi tiket travel adalah proses pemesanan salah satu produk yang dijual oleh perusahaan travel pengangkut penumpang yaitu berupa dokumen perjalanan yang berfungsi sebagai tanda bahwa pemegang dokumen tersebut berhak atas fasilitas pengantaran dari satu daerah ke daerah lain. Sistem ikut mengatur dalam pengolahan data-data atas kegiatan pemesanan tiket penumpang pada agen travel. Kegiatan memproses data tersebut dibantu dengan menggunakan komputer, maka kegiatan pemesanan tiket menjadi lebih efisien dan efektif artinya lebih tepat waktu sehingga salah satu tujuan dari agen travel tercapai secara maksimal. Dalam pemesanan tiket penumpang, petugas menjual tiket tersebut harus dengan konsisten artinya harus melalui tahaptahap penyimpanan dokumen, pencatatan dan pengolahan suatu dalam membuat schedule pemesanan, analisa atas volume pemesanan dan data mengenai pembeli dan karena komputer mempunyai kemampuan untuk memecahkan masalah, menyimpan data serta mengkomunikasikan atau menyebarkan informasi tentang agen travel.

\subsection{Agen Travel}

Biro Perjalanan Wisata merupakan bagian dari usaha pariwisata yang memberikan layanan berupa penyediaan informasi beserta pelayanan tiket dan dokumen perjalanan yang dibutuhkan oleh para wisatawan dalam melaksanakan perjalanan. Biro perjalanan wisata adalah perusahaan yang usaha dan keinginannya merencanakan dan menyelenggarakan perjalanan orang orang untuk tujuan pariwisata (tours) atas inisiatif dan resiko sendiri, dengan 
tujuan mengambil keuntungan dari perjalanan tersebut.

\subsection{Android}

Android adalah sebuah sistem operasi untuk perangkat mobile berbasis linux yang mencakup sistem operasi, middleware dan aplikasi. Android menyediakan platform terbuka bagi para pengembang untuk menciptakan aplikasi mereka (Murtiwiyati, 2013). Awalnya, Google Inc. membeli Android Inc. yang merupakan pendatang baru yang membuat piranti lunak untuk ponsel/ smartphone. Kemudian untuk mengembangkan Android, dibentuklah Open Handset Alliance, konsorsium dari 34 perusahaan piranti keras, piranti lunak, dan telekomunikasi, termasuk Google, HTC, Intel, Motorola, Qualcomm, TMobile, dan Nvidia. Perjalanan Android dimulai sejak Oktober 2003 ketika 4 orang pakar IT, Andi Rubin, Rich Minner, Nick Sears dan Chris White mendirikan Android.Inc, di California US (Hendra Nugraha Lengkong, 2015). Awalnya android dikembangkan oleh perusahaan bernama Android, Inc., dengan dukungan finansial yang berasal dari Google, dan kemudian Google kemudian membeli Android pada bulan Agustus 2005. OS Android dibangun berbasis platform Linux yang bersifat open source, senada dengan Linux, Android juga bersifat Open Source.

\section{KERANGKA PEMIKIRAN}

Dalam bab ini akan dijelaskan mengenai konsep pemikiran dari aplikasi pemesanan travel di Transwisata Travelindo berbasis android. Konsep pemikiran menjelaskan tentang gambaran sistem yang diterapkan pada aplikasi.

\subsection{Kerangka Konseptual}

Dapat dilihat dari tujuan penelitian, penggunaan media android dalam pembuatan aplikasi booking travel pada Transwisata Travelindo Malang dikarenakan media android sangat populer di kalangan masyarakat, selain itu banyak yang menggunakan media android tersebut dikarenakan kemudahan dalam pemakaiannya dan sangat membantu di dalam kehidupan sehari-hari. Sistem aplikasi booking travel dirancang dengan membutuhkan program aplikasi Android Studio yang bisa membantu dalam perancangan aplikasi booking travel pada Transwisata Travelindo Malang. Aplikasi booking travel ini sangat mudah diaplikasikan untuk para customer dari Transwisata Travelindo Malang sehingga dapat melakukan proses booking travel dengan cepat dan praktis, dan tentunya menghemat waktu. 


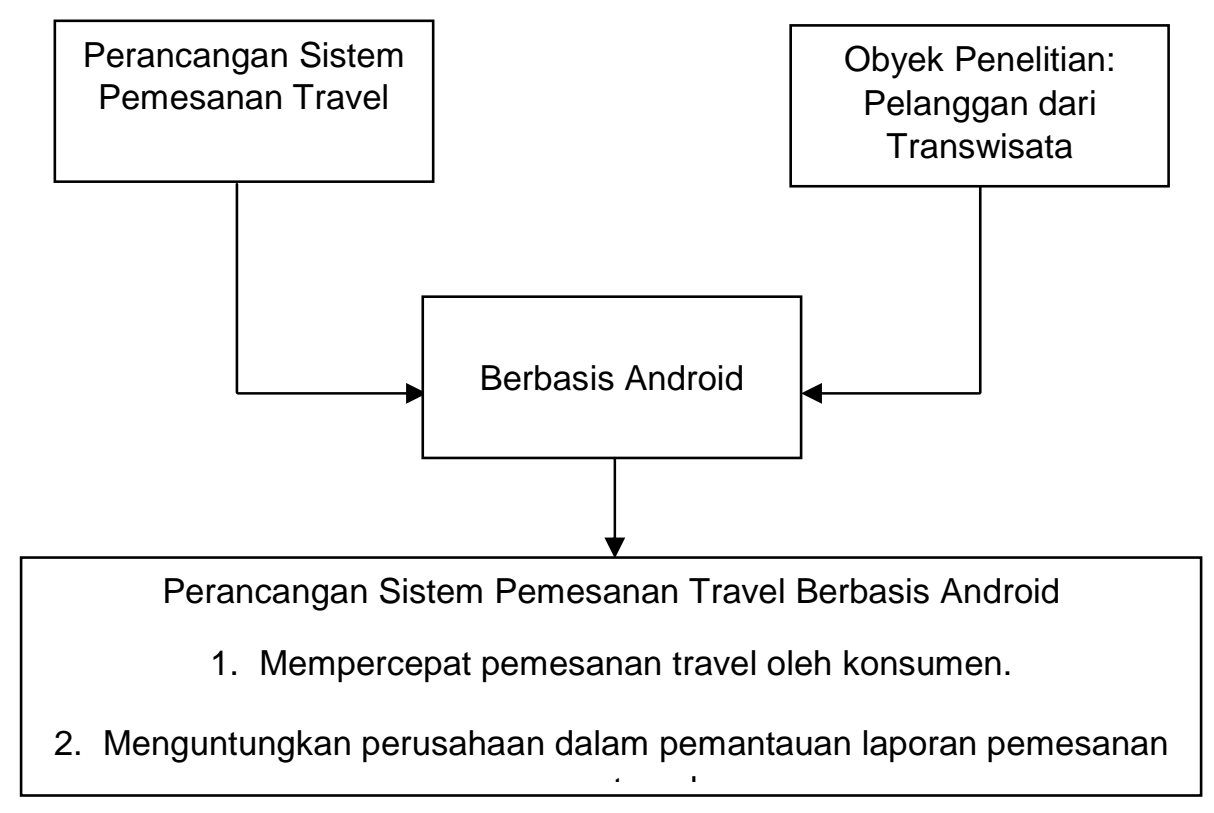

Gambar 3.1. Kerangka Konseptual Sistem Booking Travel

(Sumber: Penelitian)

\subsection{Kerangka Pemikiran}

Aplikasi booking travel berbasis android ini dapat diakses melalui perangkat android dan website yang saling terhubung sehingga dapat diakses oleh user/konsumen dan admin, seperti dijelaskan pada gambar 3.2.1 dibawah ini:

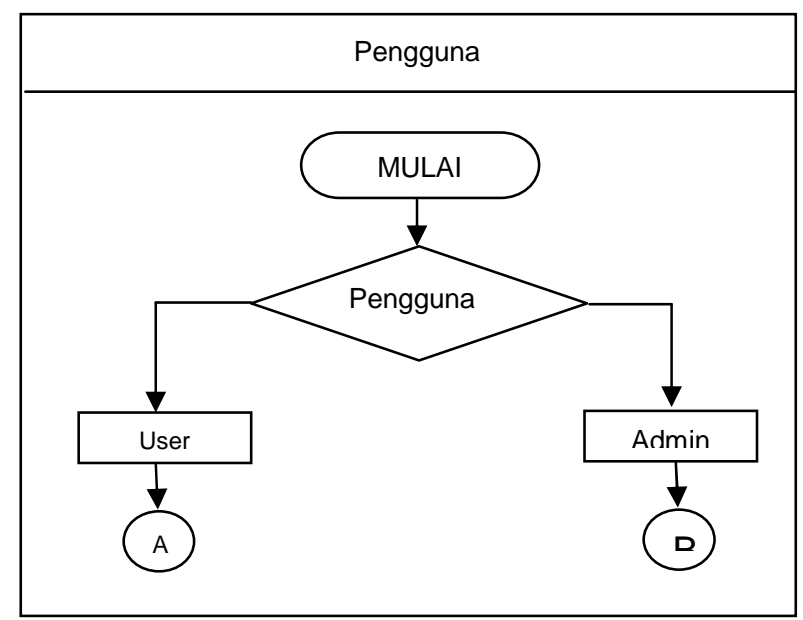

Gambar 3.2. Flowchart User pada Sistem Booking Travel

(Sumber: Penelitian) 
Pada gambar 3.2 di atas menjelaskan bahwa aplikasi booking travel dapat diakses oleh user/konsumen dan admin. Untuk pemesanan aplikasi ini hanya dilakukan oleh user dimulai dengan proses login, setelah melakukan login maka akan muncul tampilan awal yang berisi tentang menu jadwal travel, booking travel, dan menu keluar dari aplikasi.

\section{Flowchart Sistem Booking Travel}

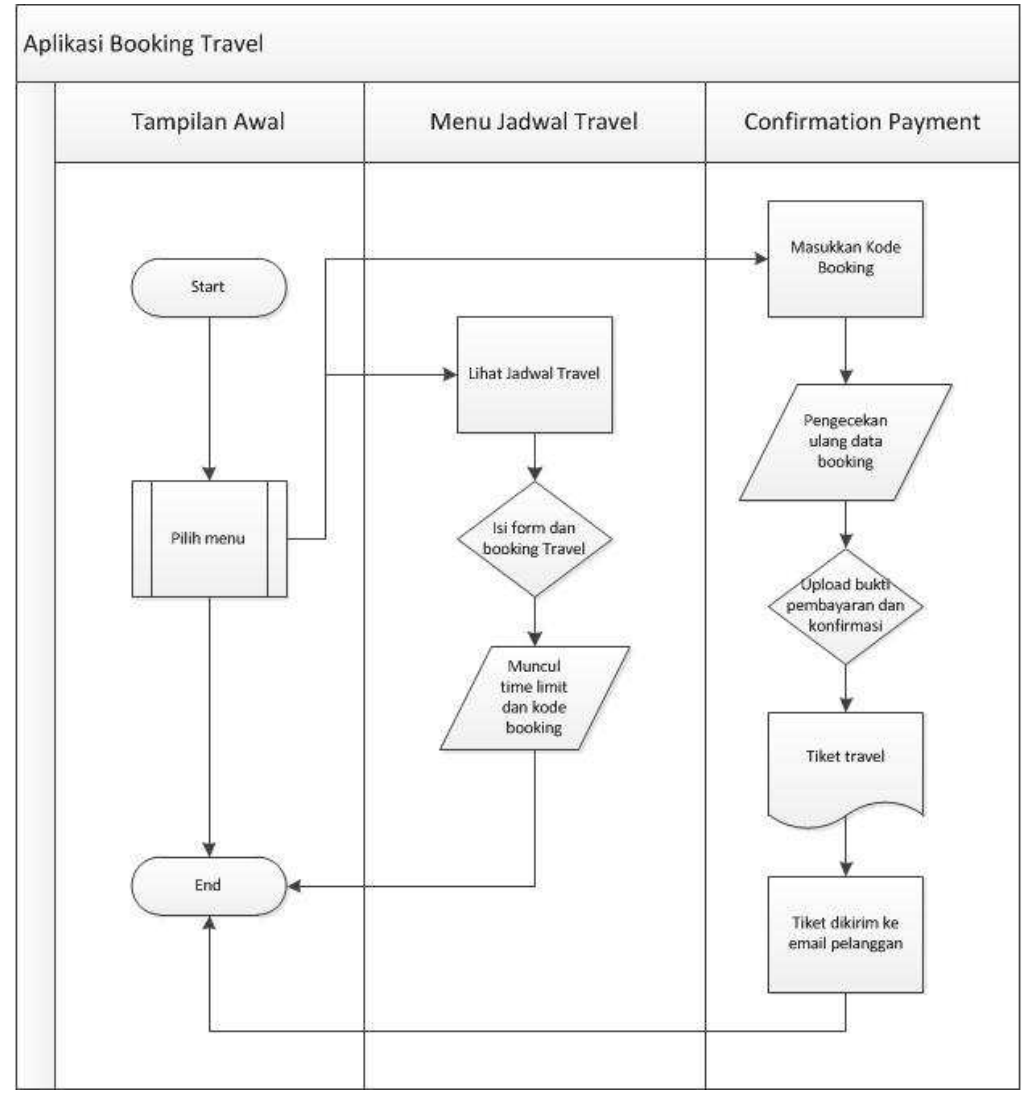

Gambar 3.2.1. Flowchart Sistem Booking Travel

(Sumber: Penelitian)

\section{Implementasi Sistem}

Untuk implementasi sistem dibutuhkan

- Menu Login User

beberapa desain tampilan yang dibuat diantaranya menu login, menu jadwal travel, dan menu history pemesanan travel. 
- Tampilan Menu Awal

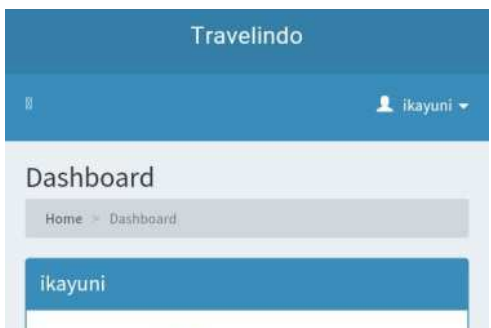

Gambar 4.2 Tampilan Menu Awal

- Tampilan Halaman Jadwal Keberangkatan

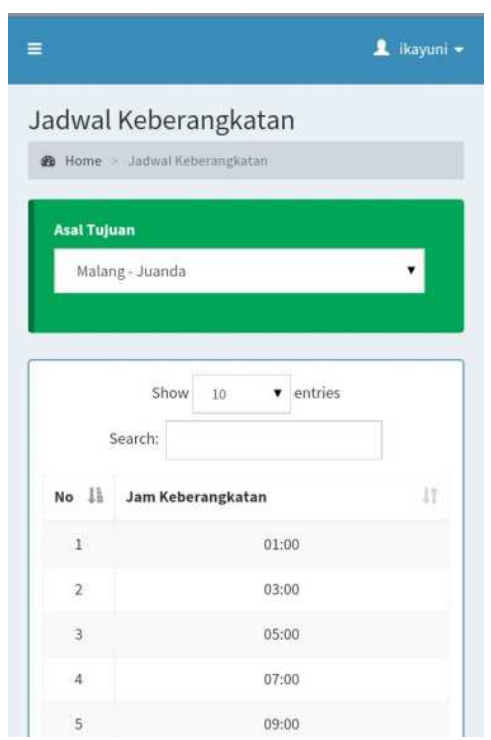

Gambar 4.3.Tampilan Halaman Jadwal

keberangkatan
- Tampilan Halaman Booking

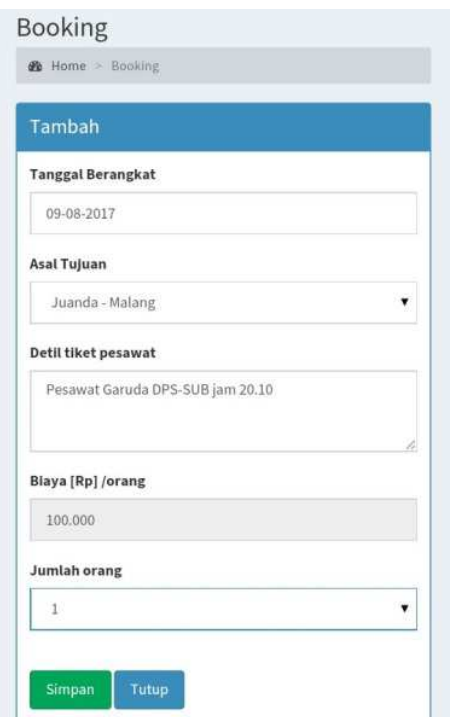

Gambar 4.4. Tampilan Halaman Booking

- Tampilan Halaman Data Booking

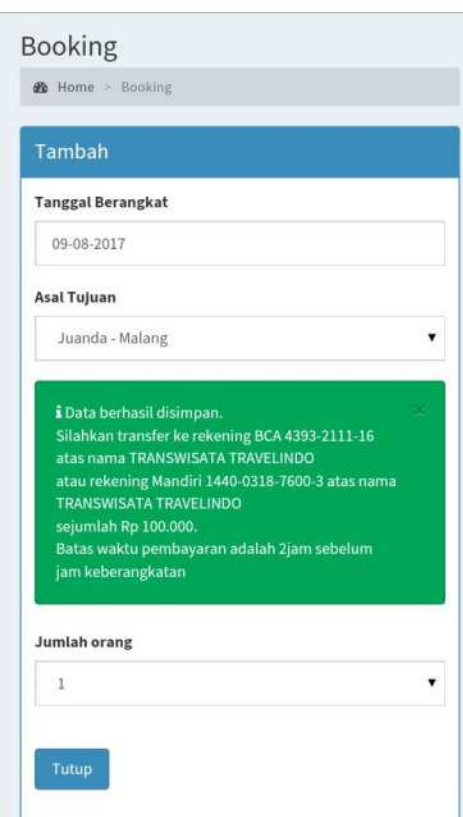

Gambar 4.5 Tampilan Halaman Data Booking 
- Tampilan Halaman Menu Upload Bukti Pembayaran

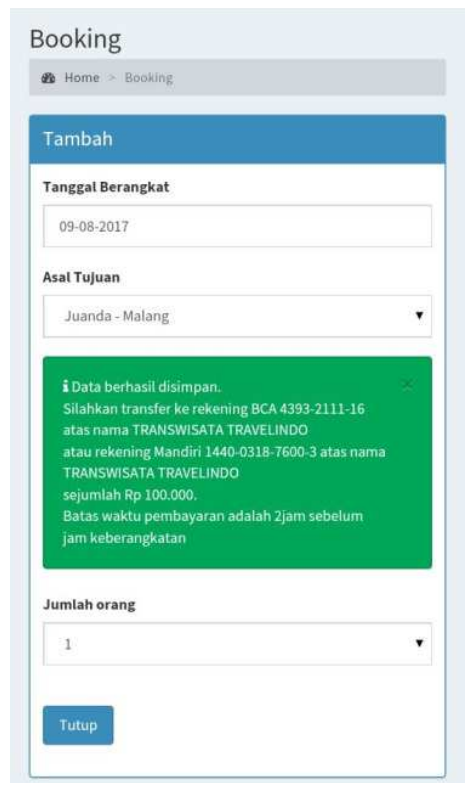

Gambar 4.6. Tampilan Halaman Menu Upload Bukti Pembayaran

\section{Kesimpulan}

Berdasarkan dari pembahasan pada bab sebelumnya, maka peneliti mengambil beberapa kesimpulan yang telah diperoleh sebagai hasil penelitian, sebagai berikut:

1. Perancangan aplikasi booking travel berbasis android tersebut dirancang dengan menggunakan PHP My Admin, MySQL sehingga memudahkan dalam pengembangan aplikasi booking travel yang lebih baik.

2. Implementasi aplikasi booking travel berbasis android pada proses pemesanan travel pada Transwisata Travelindo Malang:

a. Dalam aplikasi booking travel berbasis android ini terdapat beberapa menu yang dapat membantu dalam proses pemesanan travel bagi para konsumen Transwisata Travelindo.

b. Pada menu awal terdapat beberapa pilihan jam keberangkatan travel yang bebas dipilih oleh para konsumen sesuai dengan keinginan masing-masing.

c. Hasil dari setiap pemesanan travel akan langsung direkap di menu histori pemesanan pada aplikasi tersebut, untuk para konsumen yang telah melalukan proses booking diharapkan bisa melakukan proses pembayaran agar tiket travel bisa dikonfirmasi oleh admin travel.

d. Laporan hasil pemesanan travel bisa dilihat pada menu histori pemesanan.

\section{DAFTAR PUSTAKA}

1) Arikunto. 2010. Pengertian Data Primer (Online)

(http://eprints.undip.ac.id/40789/3/BAB _III_METODE.pdf dan diakses tanggal 01 November 2016)

2) Asiah, Hani Siti Haviani Nur dan Asep Deddy Supriatna. 2015. Pengembangan Perangkat Lunak Pemesanan Tiket Travel Berbasis Web Dan Mobile.

Bandung

3) Azwar. 1987. Pengertian Uji Validitas dan Reliabilitas (Online) (http://qmc.binus.ac.id/2014/11/01/u-ji-v-a-l-i-d-i-t-a-s-d-a-n-u-j-i-r-e-l-i-a-bi-1-i-t-a-s/ dan diakses tanggal 01 November 2016) 
4) Bilik Android. 2015. Sejarah perkembangan android (Online) (http://www.bilikandroid.com/2015/10/mengenalsejarah-dan- perkembangan.html, diakses tgl 30 Oktober 2016)

5) Dr. Sugiyono. Metode Penelitian Kuantitatif, Kualitatif dan R\&D. Alfabeta

6) Fakhrurozi. 2012. Pembangunan Sistem Informasi Travel Berbasis Web Di Baraya Travel Bandung. Bandung

7) Hapsari, Fitri dan Bambang Hidayat. 2011. Aplikasi Pemesanan Travel Pada Handphone Berbasis Sistem Operasi Android. Bandung

8) Isnandi, Indah Uly Wardati. 2014. Sistem Informasi Penjualan Tiket Pada Al Fath Tours Dan Travel Pacitan. Pacitan

9) Jogiyanto. 2005. Pengertian sistem dan reservasi tiket (Online) (http://elib.unikom.ac.id/files/disk1/626 /jbptunikompp-gdl-antonfajri-3126110-unikom_1-i.pdf)

10) Kesrul. 2003. Pengertian industry pariwisata (Online) (https://books.google.co.id/books?isbn= 6022803284, Halaman 129 dan diakses tanggal 17 Oktober 2016)

11) Kurniawan, Citra, and Nanda $F$ Wahyuono. 2018. "Rancang Bangun
Game Pewayangan Anoman Obong

Berbasis Android Menggunakan Metode Prototype.” Open Science Framework. March 10. doi:10.17605/OSF.IO/S72D9.

12) Matondang, Zulkifli. Validitas Dan Reliabilitas Suatu Instrumen Penelitian. 2009

13) Putra, Marisa Eka dan Eko Nugroho. 2014. Perancangan Aplikasi Pemesanan Tiket Mobil Berbasis Android Pada Agen Travel. Yogyakarta

14) Sinar Travel. 2015. Pengertian Booking (Online)

(https://sinartourtravel.com/2015/08/02/ pengertian-booking-dan-issued/, diakses 12 Oktober 2016)

15) Sugiyono. 2012. Pengertian Populasi dan Sampel (Online) (http://repository.upi.edu/2122/6/S_KO R_0906073_CHAPTER3.pdf dan diakses tanggal 01 November 2016)

16) Wijaya, Sugeng Hadi dan Andreas Handojo. 2015. Aplikasi Sistem Pemesanan Travel Berbasis Android pada PT. Kirana Anugerah Terindah

17) Yoeti. Pengertian biro perjalanan wisata (Online) (http: etd.repository.ugm.ac.id/downloadfile/8 5631/.../S1-2015-312604introduction.pdf, diakses tanggal 17 Oktober 2016) 
18) Yulianti, Endah dan Eko Fachtur

Rochman. 2014. Sistem Informasi

Pemesanan Tiket Travel Berbasis

Mobile Android (Study Kasus : Rahayu

Travel Selorejo-Blitar). Malang 